ditions. The mixture can be sown thick or thin depending upon how rapidly the operator travels through the field. Where grasshoppers were found to be very numerous, by walking slowly and whirling the tube regularly the mixture was scattered much thicker than where they were found to be less numerous and the operator walked at a natural gait.

It is necessary to have the oranges or lemons ground through a food grinder in order to prevent the tube from becoming stopped up by the peelings. Many farmers in these counties used old grain sacks cut in two at the middle and strapped over their shoulders in the manner shown in the photograph. One objection to using a grain sack for the bag is that the sweetened mixture penetrates through the cloth and soils the clothes of the man operating the seeder. The writer prepared a bag made of water-proof canvas which overcame this difficulty. Hardware dealers generously supplied the galvanized or tin tubes at the cost of the material plus labor, and sold them at forty cents each. The rest of the outfit was made in a few minutes at the farms. Where it was scattered with these seeders, the grasshoppers ate all of the posioned bait in a few hours and every particle of the poisoned bran was utilized. Owing to their cannibalistic habits, many grasshoppers apparently died from eating the dead bodies of their less fortunate brothers. It was estimated that 75 to 90 per cent of the grasshoppers were killed by one application of the poison bran mash, scattered by means of these seeders. Public demonstrations were given in each township in Thomas County, and the general opinion as expressed by the farmers was that this cheap and simple device made it possible for them to scatter the poison bran mixture over a much greater acreage than they had heretofore attempted. This type of seeder is recommended by the writer to any who may be supervising grasshopper campaigns in the future.

\title{
NEW PARASITE CAGES
}

By C. E. Pemberton and H. F. Willard, U. S. Buteau of Entomology, Honolulu, T. $H$.

During recent studies of introduced Braconid parasites of the Mediterranean fruit-fly (Ceratitis capitata) in Hawaii, the adoption of certain improved cages for confining the parasites has given such satisfactory results that it is considered important to plave on record a description of these cages.

A glass tube, jar or chimney, in one form or another, with one or more openings tightly plugged or covered, has been usually used by 
entomologists for confining living parasites. Of these, the plain testtube, in several sizes, or the larger sterilizing tube, have been most commonly used. These will always be necessary and for many purposes of great value. However, a free circulation of air through such cages is never possible. In some respects this is an abnormal condition for the enclosed parasites. For general breeding purposes with parasites of the fruit-fly, where moist and often decaying fruit must be placed with them, the elimination of gases from decaying fruit and the prevention of moisture-condensation on the sides of the cage is of the utmost importance.

The main principle involved in the construction of the types of cages herein described is simply one of free-air circulation. Pl. 25, fig. 1 shows the style of cage now in use by the writers. It is invaluable as a cage for the Braconid parasites now under investigation. A year's trial has proved its merits over all others for most purposes in general parasite work. It is of simple construction, inexpensive and easily made by hand. The bottom and one end are of wood, both sides and one end are of fine copper screen and the top is of glass which is fitted to slide free from the cage when necessary for cleaning, as shown in Pl. 25, fig. 2 where the glass top has been partially drawn out. In the wooden end a small opening or door is cut. The construction of the door, as illustrated in Pl. 25, fig. 2, has been found most satisfactory. It is sawed from the piece composing the end of the cage, by two oblique cuts. The cut sides of the door are then padded by covering with thin strips of cardboard tightly glued on. This door then fits snugly into the opening, is tighter than a hinged door and more easily made. The glass top is important. This permits easy observation of the parasites within, even with a binocular microscope when desired, and seems also of value in allowing necessary light to enter. The cages now in use are 7 by 3 by 2 inches in size.

The three species of Braconid parasites of the fruit-fly now established in Hawaii have been very successfully handled in this type of cage. Oviposition and feeding is quite normal. Individual lots of parasites have been kept in such cages for nearly two months without need, at any time, for cleaning the cages and without any attention being given them other than the daily removing and replacing of leaves containing drops of honey and water for food. By using such cages a great amount of time is thus saved when large numbers of parasites are being handled. Parasites confined in glass test-tubes must be removed to clean tubes every two or three days. This is a slow and laborious process when large numbers must be transferred. "Sweating" in the glass test-tube containing parasites is a great annoyance and often hastens mortality unless constant attention is given the tubes. This never occurs in the 
离

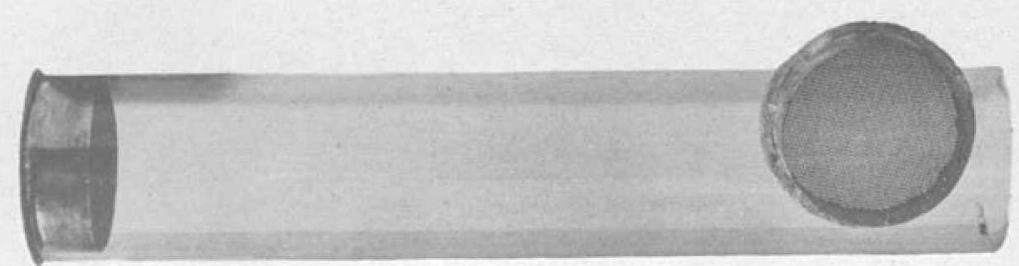

1.

葛

농

ڤ્ટ

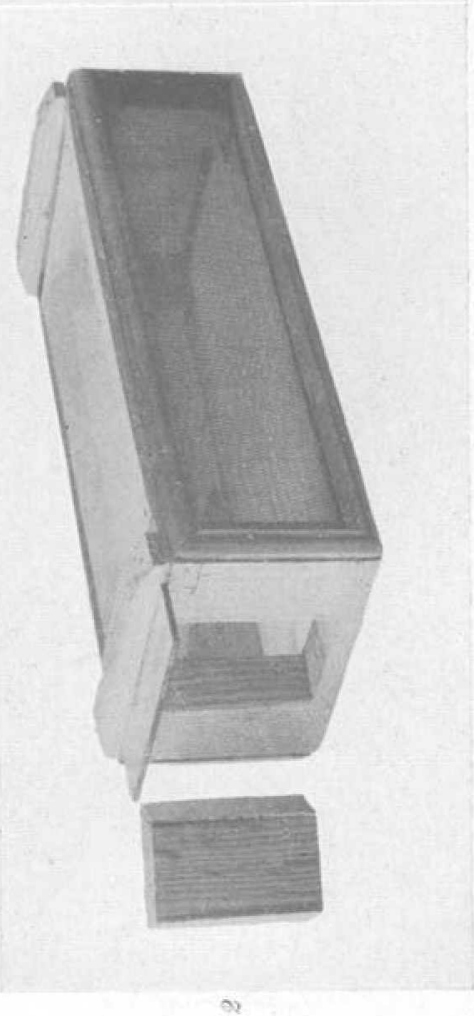

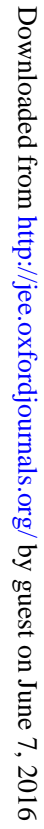

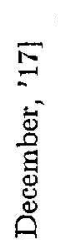

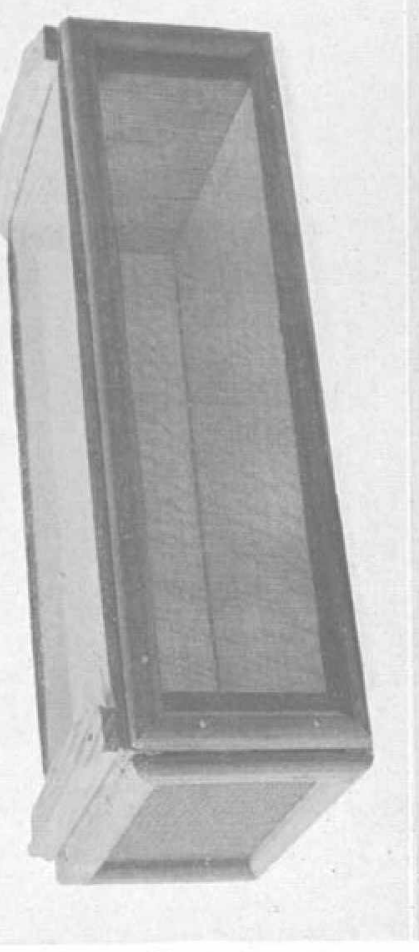

宁

总

궁

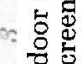

के

ㄹ⿺ㅇ

궁

8

등

$\exists$

정

ब

해영

ซึㅇㅁ

용

몽

교

政

훙ㅇㅇ

5

응

08

Q 8

is

马 क

药

영

잉

ذळ

句

के

ठํํㅇ

골 
screened box cage, even when a moderate quantity of moist or decaying fruit is placed with the parasites for a day or more.

A second type of cage, illustrated in Pl. 25, fig. 3, has been found useful and is, in some ways, also superior to the glass tube open at one end and plugged with cotton. This is a straight glass tube, 1 to $1 \frac{1}{2}$ inches in diameter and 6 to 9 inches long. It is open at both ends. Copper screened caps fit into the ends and are made just large enough to fit into place tightly. This tube also permits free air circulation within. It is of particular value as a container for individual parasites from which oviposition, or other data, is being determined. In such cases food and fruit, or other material, may be placed almost in contact with the parasite without danger of gases of fermentation accumulating and killing or injuring the individual from which valuable records may already have been secured.

Such cages as here described are of importance only in confining parasites considerably larger than the mesh of the copper screening used. The shape of the cage is not entirely essential, the free circulation of the air and abundant lighting being the important points.

These improved cages are most useful in a study of the active life functions of parasites. When it is desired simply to prolong or preserve the life of parasites, the closed test-tube or larger closed sterilizing tube is possibly better. The parasites are then best preserved and the energies least expended when given but little food and kept constantly in partial darkness.

\section{THE BIOLOGY OF CELINIDEA MEROMYZE (FORBES)}

By E. O. G. Kelly, Entomotogical Assistant, Branch of Cereal and Forage Insect Investigations

References to this parasite in literature are very few. It was discovered by Dr. S. A. Forbes in 1883, having been reared by him from the pupa of Meromyza americana at Cuba, Ill., April 25, 1883. Dr. Forbes described the parasite in his thirteenth report of the state entomologist of Illinois, as Coelinius meromyzo, stating that "the abundance of these parasites in this field may be inferred from the fact that out of fifty-five larvæ obtained here, only twenty-one developed the fly (Meromyza), and the thirty-four remaining all gave origin to Cœlinius (Cœelinidea) which continued to emerge from May 6 to May 19. Sweepings of these infested fields in April yielded none of this species, and there can be no doubt that the eggs are deposited within the bodies of the larvæ in autumn."

Dr. Forbes' conclusion was quite the natural one. No one at that 